\title{
ENTRE DOS AGUAS: UN RELATO MESTIZO DE LA FRONTERA CAUCHERA EN Colombia
}

\author{
Maria Mercedes Ortiz Rodriguez ${ }^{1}$
}

RESUMO: Dentre os aspectos relevantes contidos no presente artigo, destaca-se a análise de uma certa modernidade colombiana que, desde meados do século XIX, esteve centrada na produção gumífera e na "ocupação" de territórios que, a partir de então, passaram a despertar interesse para o "desenvolvimento" da nação. A partir desses interesses articulados aos mercados internacionais, produziu-se toda uma literatura sobre as "selvas" e os "selvagens", que habitavam os territórios amazônicos atravessados pelos rios Putumayo e Caquetá. Relatos de viagens, misto de ciência e ficção, a maior parte dessa produção literária reproduziu olhares colonialistas e eurocêntricos sobre a região e suas gentes. O foco da análise, no entanto, está voltado para a reduzida produção literária que permite apreender a presença de rostos e vozes que articulam outros pontos de vista sobre o "avanço civilizador e modernizante" para as fronteiras da borracha, na Amazônia colombiana.

PALAVRAS-CHAVE: Amazônia Colombiana. Literatura Mestiça. Fronteira da Borracha. Modernidade. Civilização.

A partir de 1850, Colombia se vinculó al mercado mundial como proveedora de quina primero y caucho después, lo cual demandó la ocupación de las selvas amazónicas del suroriente del país, surcadas por grandes ríos como el Caquetá y el Putumayo. ${ }^{2}$ Estas regiones se consideraban territorios "salvajes" y de "salvajes" y habían carecido hasta entonces de toda importancia para la nación; su ocupación se convirtió en una gesta de conquista de territorios de grupos indígenas que habían conservado hasta el momento una autonomía relativa como los uitoto, andoque, bora y miraña. ${ }^{3}$

Algunos miembros de las elites económicas, políticas y culturales de Colombia legitimaron esta conquista mediante discursos en los

1 Doutora em Literatura Latino-Americana e Espanhola, Professora da Escola de Estudos Literários da Univalle, Santiago de Cali, Colômbia.

${ }^{2}$ Según Jorge Orlando Melo entre 1881/82-1882/83, la quina representó un 30.9\% del valor total de las exportaciones de Colombia. Historia económica de Colombia, p.184.

${ }^{3}$ Según Pineda, la población de estos grupos ha sido estimada para principios del siglo XX entre 50.000 y 100.000 personas (47). 
que se combinaban las ideas dominantes de la época - la fe en el progreso, el evolucionismo y el positivismo - con la reactivación de ideas e imágenes coloniales. En ellos la selva se consideraba una fuente ilimitada de recursos y sus habitantes indígenas una mano de obra resistente y necesaria para el desarrollo de la economía extractiva. Estas ideas se superpusieron y mezclaron con otras de origen colonial en las que los indios eran representados como infieles, salvajes y caníbales; en conjunto apelaban con fuerza a imágenes sedimentadas en el imaginario hegemónico y legitimaban un régimen de colonialismo interno hacia los indígenas que posibilitaba el desarrollo de la economía extractiva. ${ }^{4}$

Algunas de estas obras son: A través de la América del Sur. Exploraciones de los Hermanos Reyes (1902) y Memorias (1986), escrito hacia 1911, del empresario, explorador y ex presidente de Colombia Rafael Reyes (1849-1921), el relato de viajes Memorándum de viaje (1905), de Joaquín Rocha, un miembro de la élite bogotana de la época, y el ensayo Reducción de salvajes (1907) del destacado político liberal Rafael Uribe Uribe. ${ }^{5}$ Estas obras presentan semejanzas con las formas retóricas utilizadas por los viajeros europeos, quienes habían escrito sus reportes a manera de diarios y diarios de viaje que no caían por completo fuera de la literatura. Había así una complicidad entre los reportes científicos y la literatura, la cual facilitó que los escritores latinoamericanos absorbieran estas narrativas (GONZÁLEZ ECHEVARRÍA, 1998, p. 96). Sin embargo, estos autores colombianos no replican los textos europeos, los asimilan en la medida en que les sirven a sus propios intereses, y los reelaboran mediados por las dinámicas de la economía extractiva y por las condiciones políticas, económicas, sociales y

\footnotetext{
${ }^{4} \mathrm{El}$ concepto de colonialismo interno fue definido entre los años sesenta y setenta por distintos teóricos latinoamericanos (Stavenhagen, 1964, González Casanova, 1970, Bonfil, 1971), quienes siguieron luego trabajando el tema. La intelectual boliviana Silvia Rivera Cusicanqui también utiliza este concepto en sus análisis. Rodolfo Stavenhagen define el concepto de la siguiente manera en Ethnic Conflicts and the Nation-State: "Las características étnicas (biológicas y culturales) de los grupos opositores se tornaron emblemáticas en el funcionamiento y mantenimiento del sistema colonial de dominación y explotación. Racismo, otras formas de discriminación y la categorización cultural de la población contribuyeron a perpetuar y acentuar diferencias étnicas que se convirtieron en marcadores de desigualdad y estratificación. Cuando tal situación prevalece en el periodo poscolonial, es mencionada a veces como colonialismo interno” (1996, p. 21) (mi traducción). ${ }^{5}$ He analizado los textos de Reyes en el artículo "Textual Forests: The Representation of Landscape in Latin American Narratives” ( Tally Jr.,2011, p. 63-75).
} 
culturales de Colombia en aquella época. La asimilación no es de ninguna manera gratuita. Al duplicar la mirada colonialista y eurocéntrica de la mayoría de los viajeros europeos sobre territorios y personas de su propio país, los convierten en el "otro," al que pueden observar, clasificar, dominar y explotar en base a su supuesta superioridad de "civilizados." La muy incipiente modernidad de Colombia a principios del siglo XX, con un débil desarrollo de la ciencia y con un fuerte legado colonial, incide en una reescritura de los textos europeos, la cual da origen a unas obras locales específicas. ${ }^{6}$

\section{Una voz mestiza}

Son pocos los textos escritos que nos permiten oír voces distintas de las de los miembros de las elites, que brinden otras visiones sobre el avance de la frontera cauchera en la Amazonia colombiana. Uno de ellos es el relato del mestizo Aquileo Tobar, hijo de un empleado de la Casa Arana y de una indígena murui - un subgrupo uitoto - del Caquetá- Putumayo, publicado como un apéndice bajo el título " La conquista de la Huitocia" en la obra La economía extractiva en la Amazonia Colombiana 1850-1930 (1990) de Camilo Domínguez y Augusto Gómez. En este texto, Tobar subvierte la retórica dominante que trata a los uitoto como "salvajes" y" caníbales", presentándolos, por el contrario, cómo los poseedores de una cultura valiosa y digna de respeto. Paradójicamente, sin embargo, describe las relaciones de los caucheros colombianos con los uitoto como pacíficas y armoniosas, basadas en el beneficio mutuo - al contrario de la mayoría de la evidencia histórica - en la cual, al igual que en los relatos de Rocha, se muestra la terrible violencia y la explotación ejercida por estos caucheros sobre los indígenas, aunque haya habido algunas excepciones.

La versión de Tobar fue recogida por el antropólogo Horacio Calle, quien, según Augusto Gómez, conoció a Tobar en 1971 en Puerto

\footnotetext{
${ }^{6}$ Carlos Uribe Celis señala la fuerza que la tradición tenía en la Colombia de principios del siglo $\mathrm{XX}$, contra la cual se empezaban a dar procesos de cambio y que define así: "Nuestra tradición - lo sabemos - era la de presidentes letrados, educación mística, escolástica y verbalista que sustentaban - en gran parte por herencia española - el lastre del leguleyismo y que tuvo su primera manifestación en la casuística de las Leyes de Indias, tal como la desarrollaban los funcionarios de la Real Audiencia y quienes con ella tenían que ver (76).
} 
Leguízamo, un puerto sobre el río Putumayo, cuando éste tenía unos cincuenta y cinco años y trabajaba como piloto de remolcadores a lo largo del río. Hablaba con fluidez el bue, uno de los dialectos del uitoto, y lo utilizaba sin ninguna vergüenza públicamente. Vivía con una mujer indígena y había escrito dos libros: una historia de las caucherías del bajo Putumayo y una autobiografía que nunca fue publicada (DOMÍNGUEZ Y GÓMEZ, 1990, p. 201).

Aquileo se presenta a sí mismo al inicio del relato como un hombre nacido en El Encanto, una estación cauchera sobre el río Caraparaná, por cuyas venas corre sangre indígena "que tiene rival con la sangre del blanco por ser impura," sin que quede claro cuál es su noción de impureza. Se refiere a su padre como un desgraciado empleado de la Casa Arana que ganaba un sueldo miserable y que fue conducido junto con su familia a Iquitos, en el Perú, posiblemente por causa de las políticas de traslado forzoso de población ejecutadas por la Casa Arana, la compañía cauchera del peruano Julio César Arana. ${ }^{7}$ En este puerto peruano sobre el Amazonas, nos refiere Aquileo, aprendió a leer, siendo ya un hombre de 22 años (TOBAR, 1990, p. 202-203).

\section{Un texto de frontera}

Mediante un condensado preámbulo de escasamente una página, Tobar sitúa su texto en relación tanto con la oralidad como con la escritura, y explica los propósitos que lo animan. Pretende con él sacar a la luz cosas escondidas, ya que "nada se hunde en el olvido por muy oculto que sea", en consonancia con la tradición - suponemos que la indígena - pero también puede incluir la de los caucheros, la cual "no calla y en toda hora va manifestando los hechos acontecidos en los tiempos pasados" (TOBAR, 1990, p. 203). Tobar

\footnotetext{
${ }^{7}$ La Casa Arana, que se convirtió luego en la Peruvian Amazon Company, contaba con capital inglés y fue la responsable del genocidio de los uitoto, andoque, bora y otros indígenas de la selva del suroccidente colombiano, a quienes enganchó a la fuerza como trabajadores en la extracción del caucho. Los caucheros torturaron y masacraron a estos grupos, conduciéndoles casi a su extinción, crímenes que fueron denunciados por el periodista peruano Benjamín Saldaña Roca en Iquitos en 1907 en los periódicos La Felpa y La Sanción, por Sir Roger Casement, delegado del Foreign Office británico, quien publicó un informe sobre la situación en 1912, conocido como El libro aqul del Putumayo y por el ingeniero norteamericano Walter Hardenburg, quien escribió en 1909 reportajes en el periódico londinense The Truth y luego, en 1912, un libro titulado The Putumayo, the Devil's Paradise.
} 
va a consignar entonces por escrito esta tradición que en su opinión no ha sido tratada apropiadamente en obras como La vorágine, en la cual se hace "somera indicación de los hechos pero sin principio y fin de las cosas. Ella se abre a narrar cosas acontecidas en el Brasil." Su misión, al escribir, es poner de presente el punto de vista de los indígenas, "para adentrarnos al principio cual fue el punto móvil para los huitotos" (TOBAR, 1990, p. 203). ${ }^{8}$ Tobar le reclama entonces a La vorágine la omisión de la historia de los uitoto, asumiéndola como una obra histórica y desconociendo su carácter de ficción. Da sin embargo en el blanco, ya que la omisión de la historia y la voz indígenas en la novela de Rivera no es casual y tiene relación con la situación legal que tenían los llamados "salvajes" dentro de la nación colombiana en aquella época y con los discursos que sobre ellos circulaban.

Este mestizo bilingüe, que navegaba entre dos culturas y que había ganado acceso a la escritura, se convierte, al identificarse con su lado indígena, en portavoz y cronista de los uitoto. Narra entonces un fragmento muy significativo de su historia, el de las caucherías; tarea que era difícil que éstos asumieran por su desconocimiento de la escritura y porque miles de ellos habían muerto a manos de los caucheros y los sobrevivientes se habían dispersado.

Este texto se ubica así dentro de lo que Martin Lienhard - siguiendo a Cornejo Polar - ha definido como literaturas alternativas en las cuales se da una apropiación de las formas culturales europeas pero cuyos referentes remiten a las sociedades marginadas de ascendencia prehispánica, las cuales provienen del conflicto cultural creado por la conquista y la subsiguiente situación colonial (LIENHARD, 1991, p. X).

Este relato sobre las caucherías fue producido dentro de una nueva conquista y se puede denominar un texto de frontera, engendrado por la pugna entre lenguas, sociedades y culturas marcadamente diferentes que son las que le dan vida y lo hacen posible. Ignoramos, sin embargo, todo lo referente al proceso de elaboración y escritura del manuscrito de Tobar. No sabemos si recurrió sistemáticamente a la tradición de otros indígenas y blancos o sí se basó en lo fundamental en su propia experiencia y conocimiento y los de sus padres.

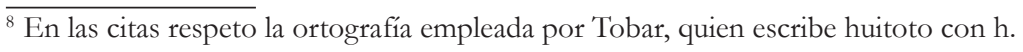


Desconocemos asimismo la época de su vida en que escribió el manuscrito y como llegó a conocerlo el antropólogo Calle, etc., información que ayudaría a arrojar luz sobre un texto difícil y desconcertante; desconcertante porque propone la utopía de unas relaciones armoniosas entre blancos e indios que se aleja por completo de su declaración inicial sobre el efecto que tuvo la civilización sobre los indígenas que los prácticamente los aniquiló:

Escribir esta obra no es un acto de pasión ni de inquina, sino una manifestación al mudo lector y a los amigos que deseen conocer el comienzo de la entrada de la civilización a las tribus indígenas; pero también entró la ruina y exterminación de la raza. Por este tiempo muy pocos son los que habitan su tierra, están dispersos por el mundo como arenas que el viento levanta y posa en otros lugares (TOBAR, 1990, p. 203) (Énfasis agregado).

Con estas frases poéticas se termina el breve preámbulo y se da comienzo a la narración propiamente dicha con la descripción concisa de los inicios de la explotación del caucho, con el fin de introducir al personaje de Crisóstomo Hernández en un tiempo y un lugar específicos. En esta descripción se contrapone la naturaleza selvática con una naturaleza conquistada ya por los colonos y caucheros. La primera estaba dotada de tierras fértiles, "que estaban esperando un día del amanecer para el progreso," en las que reinaba la abundancia de animales salvajes, aunque también las enfermedades, en la segunda se habían fundado fincas y se estaba desarrollando la agricultura. Tobar muestra aquí la influencia del discurso dominante basado en la idea de progreso ya que, al igual que el expresidente Reyes en sus obras, piensa que las selvas son un potencial que debe ser desarrollado para que produzca riqueza.

\section{Un cauchero "transculturado"}

Es en una de estas fincas en donde aparece ante el lector un grupo de caucheros entre los que se halla el moreno - es decir, afrodescendienteCrisóstomo Hernández quien, bajo los efectos del alcohol y al calor de una pelea, mata a uno de sus compañeros. ${ }^{9}$ Por no caer en manos de la justicia, Hernández

\footnotetext{
${ }^{9}$ Tobar menciona indistintamente a Hernández como moreno o negro.
} 
huye por el río Caguán abajo hasta llegar a su desembocadura en el Caquetá. En esta fuga en la que entra en contacto con los carijona primero y los uitoto después, grupos que Tobar supone que no habían tenido ningún contacto previo con los blancos; el cauchero va sufriendo un proceso creciente de "indianización." " Los indios que Tobar describe como generosos y hospitalarios, lo van incorporando a su cultura, le enseñan sus lenguas y costumbres, lo dejan participar en sus rituales y le asignan mujeres como sus compañeras. Cabe aclarar aquí que Tobar relata que el color de piel de Hernández resultó muy extraño e incluso aterrador para los indígenas quienes nunca habían visto un afrodescendiente. Es un texto que por lo tanto resulta útil también para analizar el contacto y las relaciones entre amerindios y afros.

La estadía de Hernández entre los carijona resultó corta ya que el cauchero se enamoró prontamente de una joven distinta de la que el cacique le había dado por mujer. Los indígenas se molestaron, los padres de la muchacha la reprendieron y el cauchero resolvió entonces huir con ella. Los fugitivos navegaron a lo largo del río Caquetá por seis días, viaje que Tobar describe poéticamente, ensalzando la belleza de la naturaleza selvática, a la vez que señala sus peligros, hasta que encontraron un grupo de uitoto.

El tiempo de convivencia de Hernández con los uitoto es largo, el texto habla de cuatro años, y su proceso de cambio cultural es por lo tanto fuerte. Tobar escribe que "en este ambiente y clima se humanó Crisóstomo" - que significa, según el diccionario, hacer a uno humano, familiar y amable como si fuera un nuevo nacimiento. "El hombre se familiarizó con los nativos y el cacique le dio a otra jovencita para su mujer.” Continuó viviendo entonces con las dos, la carijona con la que había llegado, y la nueva, dato revelador si se

\footnotetext{
${ }^{10}$ En la actualidad el número de carijona, según el censo del 2005 de Colombia, asciende a 425 personas, hablan una lengua que pertenece a la familia lingüística caribe y unos están ubicados en La Pedrera( Amazonas) sobre el río Caquetá y otros en el alto río Vaupés cerca de Miraflores ( González de Pérez, 2011, p. 72, 80). Los uitoto ascienden a 6.444 personas, según este mismo censo, su lengua pertenece a la familia lingüística uitoto. Su hábitat tradicional ha sido la región de los ríos Caraparaná e Igaraparaná, pero en la actualidad viven también en las orillas del Caquetá medio, por la hoya del Putumayo y cerca de Leticia. Hay algunos uitoto que habitan en Perú debido al desplazamiento ocasionado por la Casa Arana (González de Pérez, 2011, pp. 72, 117). Roberto Pineda estima para el año de 1900 el número de uitoto en 30.000 (2000, p. 48).
} 
piensa que la poligamia era en general una prerrogativa de los jefes entre estos indígenas. Este cambio se revela simbólicamente en la apariencia exterior del cauchero: "la ropa de algodón o tela se acabó. Se hizo de fibra de corteza de palo taparrabo, como los nativos". El proceso no era, sin embargo, fácil, Hernández había perdido el temor a los indígenas pero le preocupaba estar "muy apartado de sus compañeros y del pueblo civilizado" (TOBAR, 1990, p. 211).

El narrador recrea entonces el proceso de convivencia de Hernández con los uitoto, que circuló seguramente entre indígenas y también entre caucheros, según menciona Rocha, como un proceso de transculturación que subvierte los discursos dominantes sobre las relaciones interculturales. Silvia Spitta define transculturación como el proceso complejo de ajuste y recreación - cultural, literaria, lingüística y personal - que permite configuraciones nuevas, vitales y viables que surgen del choque de culturas y de la violencia de las apropiaciones coloniales y neocoloniales (SPITTA, 1995, p. 3). Se tiende a pensar que las sociedades que viven un proceso de transculturación son las sociedades invadidas por los poderes coloniales o sus sucesores, pero en este caso se trata de un cauchero, prófugo de la justicia, quien en la frontera amazónica, en donde colonos y caucheros invaden territorios indígenas, logra reconfigurar su vida gracias a los indígenas que le prestan ayuda y de quienes adopta la lengua e importantes elementos culturales.

Hernández se mueve así de la" civilización" a "la barbarie" en el sentido contrario al estipulado por el discurso hegemónico y se instala en la genealogía de personajes como Alvar Núñez Cabeza de Vaca, Gonzalo Guerrero, capturado por los mayas, las cautivas de los malones de los araucanos en Chile y Argentina, Manuel Córdova-Ríos, un cauchero capturado por los amahuaca en la Amazonia a finales del XIX, y en el siglo XX, Helena Varelo, capturada por los yanomami. Desde luego estos personajes no llegaron por gusto a la convivencia con los indígenas, fueron forzados a ella, y, sin embargo, el proceso de transculturación que viven al interior de las mismas los convierte en figuras incomodas para los sistemas dominantes que han intentado opacar siempre la realidad de Latinoamérica como un continente signado por la transculturación y la heterogeneidad. No sé hasta qué punto el hecho de que Hernández fuera un 
afro descendiente, o sea parte de lo que se definía como la alteridad en la colonia y la república, haya influido en su capacidad de adaptación a la cultura de los uitoto y en su recepción por parte de estos.

\section{Una recreación respetuosa}

En el relato de Tobar sobre la convivencia de Hernández con los uitoto se desmiente la imagen del salvaje caníbal, tan difundida en la Amazonia por los discursos dominantes y se recrean en detalle elementos esenciales de esta cultura como los mitos y los bailes que se presentan de manera respetuosa y positiva, aunque el autor nunca rompe del todo con el paradigma de civilización/barbarie pues menciona con frecuencia a lo largo del texto a los "blancos" como el pueblo civilizado, tal como se lee en la cita anterior. Con el fin de relatar lo que supuestamente vio y oyó Hernández, Tobar tiene que apelar a su propio conocimiento sobre las tradiciones de los uitoto. Este conocimiento debía provenir de la tradición oral indígena trasmitida por su madre y otros indígenas, de su infancia y de sus experiencias ya de adulto con las culturas indígenas del Caquetá, a su regreso de los años de exilio en Iquitos.

El mestizo nos ofrece en estas descripciones una síntesis que condensa varios estratos temporales que cubren el mundo de los uitoto antes, durante y después de las caucherías. En este sentido, Tobar realiza una labor similar a la que llevó a cabo el Inca Garcilaso o los cronistas mestizos mexicanos, constituir un legado cultural e histórico sobre el pueblo uitoto, consignando la tradición en la escritura para luchar contra el olvido y la muerte. Es recomponer el universo cultural después de la peor tragedia de la historia de este pueblo, las caucherias que lo llevaron casi a su total aniquilamiento. Sin embargo, esta versión está cargada de signos ambivalentes y altamente problemáticos, cómo se evidencia en el caso del mito que cita sobre el origen de los blancos. Este mito aparece en el texto cuando el cacique uitoto tiene que explicar a su gente y a sí mismo la aparición de Hernández, un negro, lo cual era algo completamente desconocido para ellos:

En la historia nuestra dice que en los confines del mundo existen habitantes de color blanco como de color negro. De esas gentes son venidos y han llegado ahora hasta nosotros y 
por lo cual son idénticos a nosotros. No ven, su cara, manos, piernas, nariz, ojos y boca, dientes y el caminar es lo mismo que nosotros. Son nuestros hermanos de otros mundos. Dios hizo muchas gentes al otro lado del mar [(manayai) en Guitoto el mar\}; por eso no hay que aborrecerlo ni odiarlo, hay que servirle en todo lo posible. Tenemos que llevarlo a nuestras casas y cuidarlo bien. Ninguno de ustedes será grosero con el blanco. Solo su color es negro pero es de los blancos (DOMÍNGUEZ Y GÓMEZ, 1990, p. 206-207).

Sí bien este mito muestra por un lado la fuerza cultural y la capacidad intelectual de los uitoto en su búsqueda de explicaciones de lo desconocido, en ese caso la existencia de un negro, por el otro evidencia la influencia del cristianismo. Se enseña entonces a los indígenas, de acuerdo al mandato del amor al prójimo, a recibir hospitalariamente a un desconocido que abrirá las puertas para su futura y nada lejana destrucción. Desconocemos las razones pragmáticas que llevaron a los indígenas a dar tan cordial bienvenida a Hernández, Tobar no dice nada al respecto, pero en casos como el CórdovaRíos se sabe que los amahuaca perseguían que este los ayudara a obtener armas de fuego para defenderse de los caucheros invasores y en el caso de Helena Valero, los yanomami buscaban establecer una alianza con los colonos que estaban entrando en su territorio mediante el matrimonio por rapto, cuál era su costumbre. ${ }^{11}$

No es casual que la llegada del cauchero al poblado uitoto coincida con la realización de un baile, ya que la descripción del mismo constituye uno de los momentos privilegiados dentro del texto para presentar la riqueza cultural de los indígenas, mostrándole al extraño quienes son y lo que valen. Los uitoto celebraban varios bailes durante el año, éste era un baile para la cosecha de un fruto, y el texto muestra muy acertadamente que estos eventos constituían

${ }^{11} \mathrm{El}$ caso de Córdova-Ríos ha sido relatado por Bruce Lamb, quien entrevistó al excauchero y curandero en Iquitos en los sesentas, en su libro The Wizard of the Upper Amazon (1971). El poeta y escritor peruano César Calvo elaboró esta historia en su obra Las tres mitades de Ino Moxo y otros brujos de la Amazonía (1981). Helena Valero relató inicialmente su historia al antropólogo italiano Ettore Biocca, quien la grabó entre 1962-63 y la publicó en 1965 bajo el título en italiano de Yanoàma. Dal racconto di una donna rapita dagli indi. Helena publicó posteriormente en 1984 su propia versión titulada Yo soy Napëyoma. Relato de una mujer raptada por los indios yanomami. 
importantes dinámicas de reproducción social y cultural. La complejidad del baile y las distintas etapas en que se desarrolla se describen prolijamente. Se muestran los diferentes mecanismos sociales y culturales que se activan durante la celebración tanto al interior del grupo como con otros grupos de fuera a los que se invita con el fin de reafirmar y consolidar relaciones de alianza. ${ }^{12}$

Los preparativos para la fiesta demandaban tiempo, trabajo y esfuerzos mancomunados. Los hombres preparaban la coca y el ambil - extracto de tabaco cocido - que eran las "drogas" del conocimiento, y las mujeres la chicha hecha de jugo de frutas con almidón de yuca. El cacique enviaba emisarios con porciones de coca y ambil para entregar a los caciques de otras unidades sociales como invitación a la fiesta. El día señalado para la celebración se tocaba el maguare, el gran tambor de los uitoto cuyos toques constituían un código de señales - ha sido llamado el telégrafo de la selva - para avisar la hora precisa en que los invitados debían llegar. Estos empezaban a llegar hacia las tres de la tarde, trayendo a su vez comida y ambil para ofrendar al cacique, dueño del baile. Durante estas fiestas, los caciques se sentaban juntos en una tribuna y se dedicaban a narrar y recapitular las tradiciones del grupo que eran las que les permitían elaborar respuestas a las situaciones que se iban viviendo, incluyendo las nuevas como la llegada de los caucheros: "Los caciques no bailan. Toda la noche se dedican a revisar la tradición, explicando todos los acontecimientos que han sucedido" (TOBAR, 1990, p. 210).

Estas tradiciones eran y son un rico y variado conjunto de distintos conocimientos, que Tobar equipara con el conocimiento occidental para destacar el valor de la cultura indígena. Contienen historias de la creación del mundo, de los hombres, los animales y las plantas; religión; la "ciencia de la curación de enfermedades" con un "científico curandero" que conoce tanto plantas medicinales como rezos y conjuros; los conocimientos de la brujería que es el poder de transformarse los hombres en animales y de enfermar y matar a los demás; la astronomía y la aritmética (DOMÍNGUEZ Y GÓMEZ, 1990, p. 209-210).

\footnotetext{
${ }^{12}$ De manera similar Pineda explica que la vida ritual entre los uitoto constituía un componente básico de la actividad social, motivaba al trabajo y constituía un mecanismo de intercambio económico y social (2000, p. 52).
} 
El tratamiento que hace Tobar de la religión de los uitoto es particularmente interesante ya que plantea que éstos conocían por tradición oral los cinco libros de Moisés o sea el Antiguo Testamento pero ignoraban por el contrario el Nuevo. Testamento. Ésta es una manera de decir que su religión ya contenía dentro de sí de manera latente algunas semillas de la fe cristiana y que estaban preparados para asimilar la evangelización. No eran por lo tanto tan infieles, ni tan paganos y salvajes como se creía, estrategia similar de alguna manera a la utilizada por el Inca Garcilaso en sus Comentarios reales, según ha explicado Margarita Zamora.

Por contraste, los elementos que definen culturalmente a Hernández ante los uitoto en primera instancia - ya que no pueden hablar con él por el mutuo desconocimiento de sus respectivas lenguas - son los elementos visibles y materiales que éste lleva consigo. Pertenecen al reino de la tecnología, y llaman poderosamente la atención de los indígenas: "el hacha de hierro, la peinilla tan cortante y la escopeta no conocida por ellos" (TOBAR, 1990, p. 206). Estos elementos, a diferencia de la filosofía, la religión o la aritmética, no tienen equivalente ninguno dentro de la cultura de los uitoto. Estos no los poseen pero, sobre todo, no los saben producir y son claramente objetos que confieren al blanco dominio y superioridad sobre los indígenas. Las herramientas metálicas y las armas eran elementos poderosos y necesarios que los uitoto y otros grupos de la región ya habían venido adquiriendo a través de redes intertribales de comercio desde el siglo XVIII como explica Pineda (2000, p. 53-54).

Estos elementos son los que posibilitan que Hernández enganche a los uitoto en el trabajo del caucho. Éste, que ha descubierto la riqueza de caucho de la cuenca del Caraparaná, les propone a los indios el intercambio de mercancías por caucho, a lo cual éstos acceden entusiasmados. Se pone así en marcha un primer negocio que abrirá en el futuro las puertas de la región a la penetración de los caucheros. Este primer negocio se describe con un lujo de detalles que no aparece en la versión que Rocha, un miembro de la élite bogotana, recogió de los caucheros y publicó en su libro Memorándum de viaje (1905). Es bien probable, por lo tanto, que haya sido consignada en la tradición oral indígena y que además Tobar la haya recreado con elementos de su propia cosecha. Se 
puntualizan en esta descripción ciertos momentos que adquieren un fuerte poder simbólico dentro de la totalidad de la narración, en términos de la futura dominación blanca en la región.

\section{La armonía imposible de la explotación cauchera}

Después de tres meses los uitoto le entregan a Crisóstomo el primer cargamento de caucho, quien lo mete en tres canoas con remeros indígenas y empieza a remontar el Caquetá con la intención de llegar a Florencia para venderlo. Pero en el camino se encuentra con su antiguo patrón, Francisco Gutiérrez, quien le recibe el caucho dándole a cambio mercancías entre las cuales se incluye aguardiente. Ya de regreso a la comunidad uitoto donde viven, Hernández le entrega los fardos de mercancías al cacique para que las distribuya pero éste no quiere hacerlo. Estas mercancías no caen bajo el dominio de los conocimientos tradicionales que él maneja y no sabe cómo manipularlas. Le encomienda entonces el reparto a Hernández, diciéndole: "en este caso tú eres nuestro jefe" háganos el bien de abrir para ver su contenido y tú serás él que mandas en el trabajo y yo mandaré mi gente en lo que ordenes" (TOBAR, 1990, p. 214).

El binomio caucho-mercancías produce así un cambio en las relaciones de poder tradicionales. Esta actitud se explica si pensamos que el jefe de maloca o capitán como lo llamaban los blancos o cacique como lo llama nuestro autor era un hombre, como explica Pineda, cuyo poder se basaba en el control de la vida ritual. El jefe de maloca era quien conocía las historias y mitos asociados a los rituales, y su eficacia para proteger a su gente contra enfermedades, brujerías, calamidades etc. Permanecía sentado en el mambeadero, mambeando coca y chupando tabaco. De esta forma trabajaba con el pensamiento y la palabra en pro de sus subalternos trabajadores o huérfanos (PINEDA, 2000, p. 51). Se le planteaba entonces el dilema de cómo incorporar estas mercancías tanto al mito como al control de la vida ritual que era la que fundamentaba su autoridad como jefe. Con el tiempo se elaboraron respuestas, como en el caso del mito del Hacha caníbal mencionado por el mismo Pineda. ${ }^{13}$

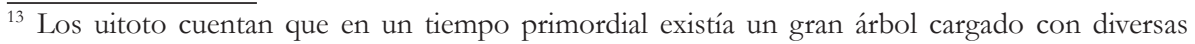
clases de frutas y productos de la chagra. Éste era efectivamente el "árbol de la abundancia," pero nadie podía tener acceso a sus frutos, porque carecía de los medios para tumbarlo. Entonces, se narra en el mito, la gente oyó decir que en el Oriente vivía una mujer Hacha, aunque ninguno 
Las noticias de los exitosos negocios de este grupo uitoto con Hernández se propagaron rápidamente entre otras comunidades de la región que, según Tobar, acudieron a ofrecerse voluntariamente a extraer caucho. El relato presenta la expansión de la frontera cauchera por la selva casi como lo hacen los cauces de agua que la surcan, como si fuera un proceso natural. El negocio se amplia, llegan más blancos a trabajar con Hernández; sus nombres se mencionan en el texto, así como las habilidades de lecto-escritura y contabilidad de algunos de ellos, a diferencia del moreno que era analfabeto como subraya Tobar. Según el texto, la seducción de las mercancías con las cuales se "cautiva el ánimo de los indios" opera a la perfección, con calma y sin violencia: "todos están muy tranquilos y contentos, tanto blancos como indios” (TOBAR, 1990, p. 217).

En la medida en que el avance cauchero se intensifica, Crisóstomo Hernández llega a dominar toda la región del río Caraparaná y parte del río Putumayo y en este contexto el narrador no puede evitar hacer una crítica a un proceso que pone en peligro su tan mentada armonía entre blancos e indios. Esta breve crítica junto con la que hace de la civilización en el preámbulo, son los dos únicos momentos dentro del texto en que el narrador cuestiona la labor "civilizadora," lo cual permite caracterizarlo como un narrador amordazado y sin libertad. La vida de las comunidades, previa a la llegada de Crisóstomo Hernández, se describe de manera idílica para insinuar el proceso de destrucción que éste y la explotación del caucho trajeron consigo:

Siguieron el descubrimiento por esas selvas cundidas de habitantes que vagaban por las selvas sólo con el objeto de

quería acercársele porque ella poseía una naturaleza caníbal. Después de diversas peripecias, Hacha corta el "árbol de la yuca" constituyéndose simultáneamente en la red fluvial del Amazonas y la agricultura regional. (Pineda, 2000, p. 49). El mito le otorga una importancia fundamental a esta mujer -hacha, ser contradictorio que quita a la vez que da. Quita a los hombres los esclavos que hay que pagar por ella - suponemos - y da nada menos que la red fluvial y la agricultura. En realidad, estos grupos ya conocían la agricultura de la yuca brava desde hacía por lo menos dos mil años pero al tener que derribar los árboles de la selva con hachas de piedra para limpiar los terrenos para la siembra, el proceso resultaba dispendioso y lento. Este mito, que es un claro resultado del contacto intercultural, pone de presente la capacidad de los indígenas de reflexionar sobre las realidades coloniales y de apropiárselas a través de sus propios sistemas de pensamiento. 
recolectar sus alimentos, del fruto de la selva. Lindas doncellas reposaban a la sombra de los gigantes árboles, niños rodaban por el suelo de hojarasca, ancianos y ancianas concretados vigilando a sus nietos y nietas que jugueteaban por el suelo, era la mansión verde del indio, no conocían la fatiga del trabajo cruel, sólo trabajaban en sus desmontes para cultivar sus granos de alimento y sus frutas; gentes sanas, las enfermedades no prevalecían en ese tiempo; en medio de ese ritmo Crisóstomo iba minando su expedición en esa raza salvaje pero noble (TOBAR, 1990, p. 218).

Se contrastan en esta descripción un antes y un después de la vida de los indígenas en la selva que se asimilan de cierta manera a un paraíso y un infierno. $\mathrm{Y}$ en lo que al infierno respecta, hay dos elementos que se le pueden atribuir claramente a los blancos, el cruel trabajo y las enfermedades. La utilización del gerundio minando apunta así mismo a señalar destrucción y, finalmente, se subraya que los indígenas son nobles a pesar de su salvajismo y que tal vez no merecían haber corrido esa suerte.

En el párrafo inmediatamente siguiente se presenta, por el contrario, a Hernández cómo alguien preocupado permanentemente por el bienestar de los indios, el bondadoso intermediario .entre el mundo de la selva y el de la civilización, entre los indios y los blancos. Se le asimila en cierta forma a un jefe de maloca; él es el capitán que maneja los "rituales" desconocidos de las mercancías y los negocios y que vela por el bien de los uitoto. Nunca permitió una ofensa a los indios y a todos sus compañeros les consiguió mujeres a través de los caciques (TOBAR, 1990, p. 218).

Con estas uniones se empieza a gestar una nueva cultura dentro de la cual creció el mismo Aquileo Tobar y el texto no logra ocultar el racismo existente hacia los indios e indias y la situación de desigualdad en la que se les colocaba al describir la mecánica de estos "arreglos matrimoniales:" "a todos sus compañeros les hizo dar mujer pidiéndolo a los caciques y a los padres de las jóvenes, y por gratitud el blanco que recibía una muchacha le regalaba alguna prenda de vestir a los padres y la muchacha era orgullosa mujer de un blanco" (TOBAR, 1990, p. 218). El proceso es una compraventa vergonzosa en el que se supone que la joven uitoto ganaba por el mero hecho de irse a vivir 
con un blanco, así fuera este un hombre rudo e ignorante, y no sabemos hasta qué punto este proceso era voluntario. Se violaban aquí por completo las reglas tradicionales en las que el novio tenía que demostrar sus habilidades para cazar, pescar y tumbar selva para las chagras agrícolas, trabajando medio año para su suegro como explica Steward (756), además tenía también que dar regalos como una pila de leña o una bolsa grande de coca.

El texto termina el relato de las "hazañas" de Hernández, explicando como éste organizó la explotación del caucho en el Caraparaná mediante estaciones que quedaron a cargo de "sus empleados de letra y contabilidad" (TOBAR, 1990, p. 218). La visión de Tobar sobre la conquista de la Huitocia difiere notablemente de la de Rocha quien la presenta como un proyecto basado en el uso de la violencia. Responsabiliza sin embargo a los indios de esta situación, ya que al no querer trabajar, por ser unos "haraganes" forzaron a los blancos al uso de la fuerza. La imagen del "bondadoso" jefe blanco no aparece tampoco en el relato de Rocha, quien siempre se refiere a Hernández como un individuo cruel y sanguinario. Ambas versiones coinciden en el proceso de transculturación vivido por Hernández, que le permitió adquirir un dominio de la cultura de los uitoto que desde luego aprovechó para organizar y manejar su negocio del caucho con métodos que varían en los dos relatos. Cabe resalta aquí la mitificación que Rocha hace en estos aspectos de Hernández a pesar de saber con claridad la clase de individuo que este era:

Es posible que el Crisóstomo Hernández que presenta Tobar sea una condensación de distintas historias sobre distintos blancos ya que existe información en otras fuentes sobre casos excepcionales de algunos que trataban bien a los indios. Es posible también que algunos los caucheros iniciaran su relación con los indios de manera amistosa mientras los conocían y adquirían confianza en el terreno. Rocha no menciona que Hernández haya vivido entre los carijona. Roberto Pineda Camacho, citando a Abel Calderón, refiere que fue un señor Cuellar de origen pastuso quien estableció los primeros contactos con los carijona. Cuellar se desposó con una mujer de este grupo y les enseñó a extraer cera de castilla que comerciaba con ellos a cambio de mercancías (CAMACHO, 2000, p. 57). El etnógrafo alemán Konrad Theodor Preuss cuenta igualmente la historia de otro blanco, Leonardo Cabrera, quien había vivido con los uitoto 
y adoptado su lengua y sus costumbres, se había constituido en su protector y benefactor y había tenido una hija con una mujer uitoto (PREUSS, 1994, p. 20-28). La cadena de relatos orales sobre Crisóstomo y otros caucheros llegó hasta José Eustasio Rivera por boca de Custodio Moreno, quien estuvo en 1905, como coronel del ejército colombiano, en las selvas del Caquetá y el Putumayo, como explica Neale-Silva, el biógrafo de Rivera. Custodio describía a Hernández como "un mulato sanguinario y taciturno, prófugo de presidio, que estaba loco" (NEALE-SILVA, 1960, p. 105).

Terminado el relato sobre Crisóstomo se abre paso a un nuevo personaje en la narración de Tobar: Benjamín Larrañaga, otro analfabeto, quien acompañó a Reyes en su primera incursión por las selvas del Caquetá Putumayo, y quien trabajó como cascarillero primero y cauchero después, terminando finalmente vinculado a la casa Arana. Se le menciona en el informe de Sir Roger Casement como un torturador y un feroz asesino de indios y aparece en las páginas de La vorágine con estas mismas características. Larrañaga incorporó nuevas áreas del Caquetá y nuevos grupos indígenas a la explotación del caucho, aprovechando la labor pionera de Hernández y la "buena fama" que éste había consolidado para los blancos según Tobar. Los indios que "también deseaban tener un blanco que les suministrará artículos,” aceptan a Larrañaga, quien finalmente se funda en un lugar llamado La Chorrera por sus grandes rápidos y que el escritor mestizo considera erróneamente que es lo que se llama Pasto hoy en día.

El relato concluye en su párrafo final reiterando la idílica convivencia entre blancos e indios, en la que, sin embargo, se pone de presente la dominación de los primeros sobre los segundos:

Todo marchaba en armonía, los pocos blancos que había eran los dioses de los indios. Cada hombre blanco tenía de dos mujeres en adelante porque los padres de las jovencitas daban sus hijas al blanco y era una dicha para el indio que su hija fuera mujer del blanco. Sólo Benjamín no pudo tener dos mujeres por el profundo respeto a su señora. Así transcurrieron los años, los indios en perfecta calma y bienestar, las enfermedades no prevalecían, las criaturas no morían y en época de verano jóvenes y jovencitas en grupos vagaban por la selva muy 
tranquilos disfrutando de su inocencia, doncellas vestidas del verde de la selva y que el único vestido era su piel color cobrizo le servía como adorno en su talla de indio (TOBAR, 1990, p. 226).

La imagen de la selva edénica se asoma aquí con la misma intensidad que en Memorias de Reyes, mas no es un paraíso virgen que hay que conquistar y poblar para el progreso de la nación. Esta selva ya está poblada por caucheros, indios y mestizos. Se ha gestado un nuevo mundo en el que los indios han aceptado felizmente el dominio de los blancos, y les han entregado a sus hijas para que les mejoren su raza inferior. Todo está bien, todo funciona perfectamente en este paraíso de nuevas alianzas en las que el escritor mestizo, producto de las mismas, a pesar de haber rescatado con orgullo elementos de la cultura uitoto de su madre, cubre con un velo la violencia del orden patriarcal que constituye la otra cara de su historia. El texto revierte la historia hacia el origen del mundo cuando no había pecado y reinaba la inocencia, nos lleva de nuevo al paraíso perdido de un mundo idealizado que existía antes de las caucherias y que él equipara con el Edén. ¿Con qué sentido? ¿Un mensaje de salvación y redención? ¿Una fuga sin límites del horro y el exterminio? ¿La posibilidad de otra historia, de otro desenlace del encuentro intercultural si en vez de las reglas que rigen los negocios en el mundo de los blancos se hubieran seguido las de intercambio y alianza que rigen el mundo indígena? Esta última sería una crítica fecunda a la realidad ya que muestra que habría sido posible, al menos culturalmente hablando, otra dirección en la historia que nos libra de aceptar lo sucedido como lo meramente inevitable.

El texto de Tobar realiza una gran labor de mediación entre los mundos tan diversos social, cultural y lingüísticamente que entran en contacto en esa frontera o zona de contacto que es la selva amazónica. Ninguno de los otros textos que hemos analizado ofrece una descripción tan detallada, consistente y rica en información sobre las culturas indígenas, presentando elementos tan importantes como los rituales y los mitos. Su origen y su conocimiento del bue - una variante dialectal del uitoto - y el español le permitieron el acceso a una información que estaba vedada para estos otros 
autores, aunque éstos tampoco tenían gran interés en la cultura de unas gentes que veían como salvajes e inferiores. Su texto es representativo, tanto como el mismo Tobar, de una tradición de frontera en la que se entremezclan y entretejen las tradiciones culturales de invasores e invadidos. ${ }^{14}$ En ella aparecen distintas versiones sobre el encuentro entre indios y blancos cuyas relaciones, creadas a partir de la extracción del caucho, son las que la estructuran.

Esta tradición se alimentaba de una nueva cultura que surgía del terror, la violencia y la convivencia, casi siempre impuesta, de trabajadores, peones y caucheros con mujeres indígenas; y en la cual evidentemente se intentó suprimir lo indígena por "impuro", por "inferior." Pero "nada se hunde en el olvido," nos dice Tobar, y él con su palabra saca a la luz elementos de esas culturas indígenas, oprimidas y suprimidas, en una versión que a veces no deja de tener sus marcados tintes de idealización. Asombrosamente no idealiza sólo a los indios, sino también a los caucheros, esos hombres que Rocha ha caracterizado como bárbaros, violentos y analfabetos, delincuentes y prófugos de la justicia muchos de ellos, como el mismo Crisóstomo Hernández. Mediante esta idealización crea una inversión de la conquista de la Huitocia, un horizonte utópico en el que se armonizan las relaciones entre blancos e indios, tratando de suprimir la historia de etnocidio y genocidio que los blancos introdujeron en la región del Caquetá.

Tobar se esfuerza, al igual que lo hizo el Inca Garcilaso, por lograr la armonía entre los dos mundos que lo han constituido como mestizo. Sin embargo, como señala Cornejo Polar, esta imagen de la armonía que construye trabajosamente el discurso mestizo del Inca, aparece más "como el doloroso e inútil remedio de una herida nunca curada que como la expresión de un gozoso sincretismo de lo plural" (POLAR, 1993, p. 75). El mestizaje, entendido como la mutilación de la totalidad de una cultura y sus seres que la conquista hizo pedazos

${ }^{14}$ La vorágine también se alimenta de esas tradiciones de frontera, aunque privilegia la voz de los caucheros y deja a los indios en el olvido en estrecha continuidad con los textos de Reyes, Uribe Uribe y Rocha. El indio sigue siendo un salvaje en la novela, aunque se omiten las insistentes menciones sobre el canibalismo, y un excluido de la nación colombiana. Si se les reclama en uno o dos momentos como colombianos, ello obedece a las necesidades tácticas del momento histórico especifico al igual que en el texto de Uribe. La riqueza y complejidad cultural que nos presenta el texto de Tobar es algo que no aparece ni someramente en la novela de Rivera. 
- y en nuestro caso la explotación del caucho - y no como la armonía entre dos mundos a la que apuesta Garcilaso, termina por reinstalarse en el discurso que lo ensalza en su condición ambigua, equivoca y precaria, que convierte la unión no en armonía sino, por el contrario, en convivencia traumática, dolorosa y difícil. Esta convivencia se cuela por hendijas y fisuras en el texto de Tobar, a pesar de los esfuerzos de este por diluirla: la superioridad tecnológica de los caucheros y el ansia de los indígenas por sus mercancías, el desdén de los "blancos" hacia las mujeres indígenas, a quienes compran por míseras baratijas, el trabajo al que someten a los indígenas y la extinción a la que los conducen, como se expresa fugaz pero significativamente en algunos pasajes del texto.

Los uitoto, sin embargo, al igual que los quechua, lograron reconstituirse como pueblo, evidentemente no en las mismas condiciones, e iniciaron un nuevo ciclo en su historia, en un contexto signado por la presencia de la misión capuchina. Las localidades indígenas adquirieron un carácter multiétnico y se crearon también nuevos asentamientos ligados a las misiones, centros de colonización etc. El gobierno colombiano compró por el valor de 200.000 dólares los derechos de la Casa Arana en el Putumayo, negociación que finalizo en 1964. Cabe resaltar que resulta asombroso que se haya compensado a esa compañía que causó la muerte a 30.000 uitoto. En 1988, el gobierno nacional ordenó la constitución del resguardo del predio Putumayo en los territorios pagados a los sucesores de Arana, que fue entregado a los nativos de la región por Virgilio Barco, el presidente de aquella época. Así, el estado reconoció por primera vez el derecho de estos indígenas amazónicos a sus tierras y selvas. En 1991, una nueva constitución declaró a Colombia un país pluriétnico y multicultural y garantizó el derecho de los pueblos indígenas a sus territorios, lenguas, culturas y autoridades (PINEDA, 2000, p. 227-228).

En la actualidad, al igual que numerosos pueblos indígenas de Colombia, los uitoto enfrentan los problemas causados por el narcotráfico y el conflicto armado, la minería y la extracción ilegal de madera. Han luchado por resolver los dilemas de estos tiempos difíciles mediante la creación de organizaciones y la persistencia, como explica Marco Alejandro Tobón, en continuar su modo de vida y sus prácticas autónomas de producción económica (TOBÓN, 2006, p. 173). Esta intrusión de grupos armados en sus territorios no es por lo demás algo nuevo para ellos ya que el recuerdo de la Casa 
Arana y de sus infames atropellos continua vivo en la memoria de los ancianos quienes homologan a los caucheros del pasado con los militares del presente y los conciben "como 'gente armada' cuya presencia y control estropean las prácticas del trabajo, y por implicación, la vida social local” (TOBÓN, 2006, p. 163) y si tuvieron la fuerza cultural para reconstituirse después de la hecatombe cauchera, esperemos que la tengan ahora para sobrevivir al conflicto actual.

\title{
IN BETWEEN THE WATERS: A MESTIZO HISTORY OF THE COLOMBIAN RUBBER BORDER
}

\begin{abstract}
The aim of the article will be analysing the process of modernisation in Colombia which in mid-19th century arose from rubber production, subsequent to the occupation of territories which became the source of the country's development ever since. Hence a "rain-forest literature" arose depicting the "savages" living the Amazon area between the Putumayo and Caquetá rivers, consisting of travel journals which, blending science and fiction, analysed the region and its people from a colonialist and Euro-centric standpoint. The article will focus on the aforementioned niche literature, which articulates viewpoints that diverge from the "civilising and modernizing progress" in the Colombian Amazon.
\end{abstract}

KEYWORDS: Colombian Literature. Mestizo Literature. Rubber Border. Modernization. Civilization.

\section{Referencias}

CAMACHO, R. P. Holocausto en el Amazonas. Una historia social de La Casa Arana. Bogotá: Planeta Colombiana Editorial S.A, 2000.

CASEMENT, R. Libro Azul BRITÁNICO. Informe de Roger Casement y otras cartas sobre las atrocidades en el Putumayo. Trad. Luisa Elvira Belaunde. Lima: CAAAP/ IWGIA, 2012.

DOMÍNGUEZ, C. \& GÓMEZ, A. La Economía Extractiva en la Amazonia Colombiana 1850-1930. Bogotá: COA, 1990.

GÓNZALEZ ECHEVARRÍA, R. Myth and Archive. A Theory of Latin American Narrative. Durham and London: Duke University Press, 1998.

HARDENBURG, W. The Putumayo, the devil's paradise; travels in the Peruvian Amazon region and an account of the atrocities committed upon the Indians therein. London: T. 
Fisher Unwin, 1913.

LAMB, B. F. Wizard of the Upper Amazon. The Story of Manuel Córdova-Ríos. Berkeley: North Atlantic Books, 1974.

LIENHARD, M. La voz y su huella: escritura y conflicto étnico-cultural en América Latina, 1492-1988. Lima, Perú: Editorial Horizonte, 1992

MELO, J. O. Historia Económica de Colombia. Comp. José Antonio Ocampo. Bogotá: Imprenta Nacional de Colombia, 1997. 231-277.

NEALE-SILVA, E. Horizonte humano. Vida de José Eustasio Rivera. Madison: U of Wisconsin Press, 1960.

ORTIZ RODRIGUEZ, M. M. Textual Forests: The Representation of Landscape in Latin American Narratives. En TALLY JR., Robert T. Geocritical Explorations. Space, Place and Mapping in Literary and Cultural Studies. New York: Palgrave Macmillan, 2011. 63-74.

POLAR, A. C. El discurso de la armonía imposible: (El Inca Garcilaso de la Vega: discurso y recepción social). Revista de Crítica Literaria Latinoamericana, 19(38), 1993.73-80.

PREUSS, K. T. Religión y mitología de los uitotos. Primera parte. Trad. Ricardo Castañeda Nieto. Bogotá: Editorial Universidad Nacional, 1994.

RAMA, A. Transculturación narrativa en América Latina. México, DF: Siglo Veintiuno, 1982.

REYES, R. Memorias 1850-1885. Bogotá: Fondo Cultural Cafetero, 1986.

REYES, R. A través de la América del Sur. Exploraciones de los hermanos Reyes. Barcelona: Ramón de S.N. Araluce, 1902.

RIVERA, J. E. La vorágine. Edición por Montserrat Ordoñez. Madrid: Cátedra, 2002.

ROCHA, J. Memorándum de Viaje. Bogotá: Editorial El Mercurio, 1905.

STAVENHAGEN, R. Ethnic Conflicts and the Nation-State. London: Macmillan Press Ltd., 1996.

SPIT'TA, S. Between Two Waters: Narratives of Transculturation in Latin America. Houston, Tx.: Rice University Press, 1995

STEWARD, J. H. The Witotoan Tribes. En Stewart, JULIAN H. (Ed.). Handbook of South American Indians, v. 3. New York: Cooper Square Publishers, INC., 1963. $747-$ 762.

TOBAR, A. La conquista de la Huitocia. En DOMÍNGUEZ, Camilo \& GÓMEZ, Augusto. La Economía Extractiva en la Amazonia Colombiana 1850-1930. Bogotá: COA, 1990. 202-226. 
TOBÓN, M. A. Cultivar la chagra en tiempos de conflicto. Los protagonistas de la guerra y la Gente de centro. El trabajo como diferenciador. Universitas Humanística, 66, 2008.155-176

URIBE CELIS, C. Los años veinte en Colombia: ideología y cultura .Bogotá: Ediciones Aurora, 1984.

URIBE, R. Reducción de salvajes. Cúcuta: Imprenta de "El Trabajo,"1907

VALERO, H. Yo soy Napëyoma. Relato de una mujer raptada por los indios yanomami. Ed. por Emilio Fuentes. Caracas: Fundación La Salle de Ciencias Naturales, 1984.

ZAMORA, M. Language, Authority and Indigenous History in the Comentarios Reales de los Incas. New York: Cambridge UP, 1988.

Data de recebimento: 19/07/2014

Data de aceite: 20/08/2014 